\title{
Mutual influence between surface fire propagation and a tree trunk
}

\author{
J. M. C. Mendes-Lopes, J. M. P. Ventura \& N. M. G. Santos \\ IN+; DEM-IST Technical University of Lisbon, Portugal
}

\begin{abstract}
Computational modelling of fire propagation is becoming one of the main tools for forest fire studies. Complex physical models are coping with increasingly larger scales and meshes that no longer can accommodate trees at individual level. Therefore, it is important to know how fire propagation is influenced by tree trunks under windy conditions in order to include that information in the model and in the cells that contain trees. It is also important to know how the flame affects the trunk, especially in its leeward side where the flame may stay attached.

To gather that type of information, a set of experiments was performed in a wind tunnel especially prepared to carry out fire propagation tests in forest fuel beds. A Pinus pinaster trunk was mounted vertically in the centre of the $1.70 \mathrm{~m}$ long measuring zone. Temperature time profiles were measured in the windward, lateral, and leeward sides of the trunk, with three thermocouples vertically aligned in each of those three sides. Rate of spread, flame angle, and flame height were obtained from video movies, as well as flame height and residence time of the attached flame in the near-wake of the trunk.

Qualitative and quantitative results show that flame propagation is not particularly sensitive to the trunk's presence, except in the near-wake of the trunk. Under certain circumstances, flames attached to the leeward side of the trunk can be much taller than the flame's main body and can remain in that zone for longer periods than elsewhere.

Keywords: fuel bed, flame propagation, rate of spread, tree trunk, Pinus pinaster.
\end{abstract}




\section{Introduction}

Forest fire studies rely heavily on computational modelling [1-9]. However, there are limitations to the level of detail these models can reach. Individual tree consideration is usually not achievable; therefore, information about the interaction between the fire and tree trunks must be gathered, to be incorporated in the models which are under development. This is especially important in prescribed fire, where tree survival has to be assured.

In the literature there are numerous studies on the biological effect of fire in tree trunks (see, e.g. [10]), but with few exceptions (e.g. [11]) there is a clear lack of data on the interaction of fire and trunks.

\section{Experimental facility}

\subsection{Wind tunnel and associated equipment}

To gather that type of information, a set of experiments was performed in a low speed wind tunnel especially prepared to carry out fire propagation tests in forest fuel beds [12] (fig. 1). The exit of the wind tunnel is $1.20 \mathrm{mx} 0.90 \mathrm{~m} \mathrm{(w} \mathrm{x} \mathrm{h).}$ The width of the working section used was the same as the tunnel width, and its length was $3.40 \mathrm{~m}$. It was open at the top and had two removable sidewalls along its total length. One of the walls was transparent (tempered glass), allowing optical access and video recording of the experiments. A mirror was placed above the working sections at an angle (adjustable) close to $45^{\circ}$. This mirror allowed seeing the work section from above, hence allowing to see (and video record) the flame propagation simultaneously from the side and the top.

The fuel bed was mounted on a tray made of wood and insulated on the top surface with compacted refractory wool. It occupied the last $2.80 \mathrm{~m}$ of the working section, and the measuring zone the last $1.70 \mathrm{~m}$. The fuel bed occupied only the central part of the tray $(0.70 \mathrm{~m}$ wide), leaving a $0.25 \mathrm{~m}$ strip on each side covered with gravel. The central part of the tray had a circular hole at half

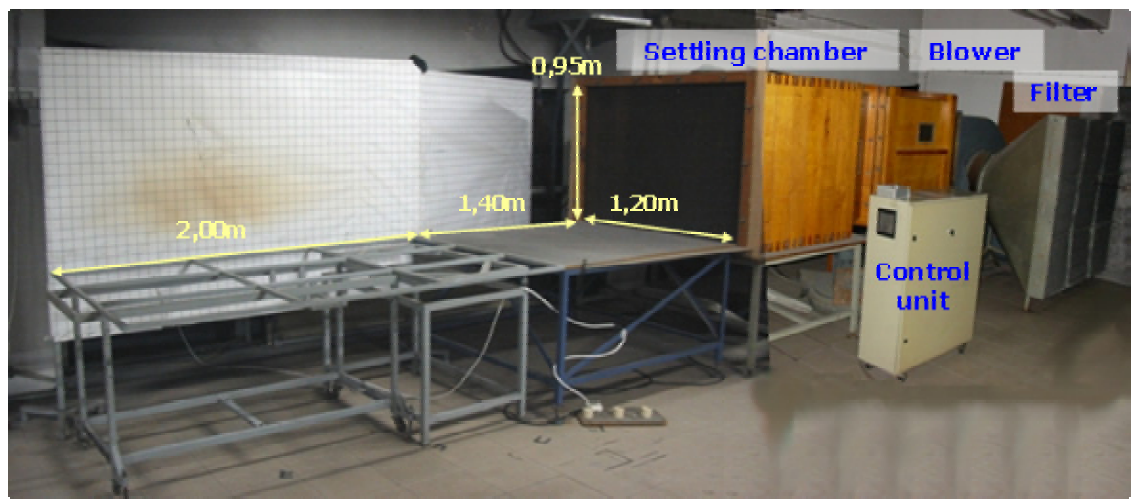

Figure 1: $\quad$ Low speed wind tunnel (with the near-side side wall removed). 


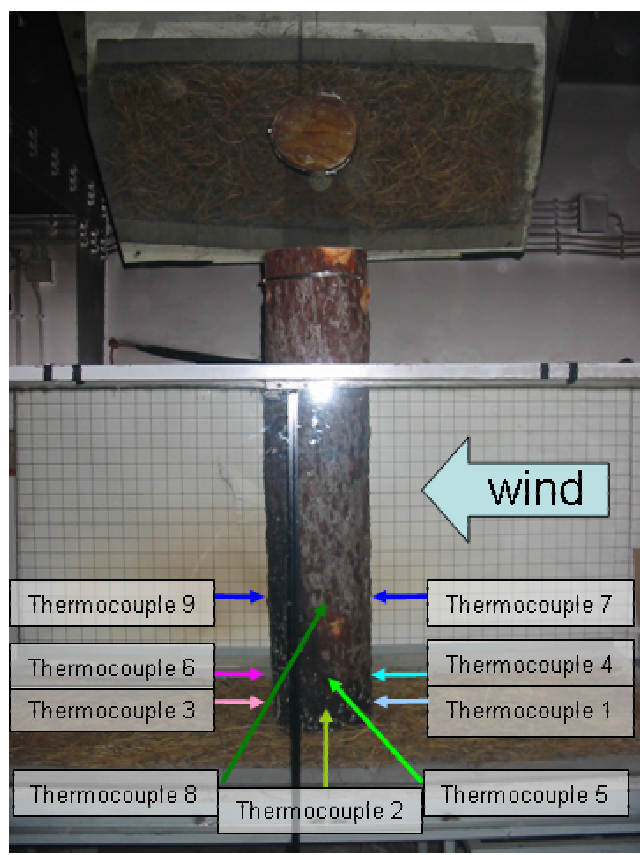

Figure 2: $\quad$ Location of the thermocouples.

length of the measuring zone, where a vertical tree trunk $(\phi=23 \mathrm{~cm})$ was located. The tree trunk was instrumented with thermocouples (three in its windward side, three in its lateral side, and three in its leeward side) at $50 \mathrm{~mm}, 100 \mathrm{~mm}$, and $300 \mathrm{~mm}$ above the tray's level (fig. 2).

Flame temperature was measured with type-J thermocouples. The dimensions of the thermocouple's wire and bead depend on the purpose of the measurement and on the mechanical resistance required. Only mean values were needed (changing rapidly but not in the turbulent time scale). Hence $250 \mu \mathrm{m}$ wire was used. The thermocouple itself provided the averaging effect needed to obtain the mean values sought [12]. When measuring air temperature with thermocouples in the vicinity of a flame, the thermocouples should be shielded. Alternatively, a correction for radiation can be applied, but this may be difficult if the flame is moving and/or is turbulent. For sooty flames (like those found in forest fires), neither radiation correction nor shielding is necessary if/when the thermocouple is inside the flame. Hence, because the temperature inside the flame was the most important aspect in these experiments, neither shielding nor corrections have been used in the reported results [12].

The thermocouples were connected to a Campbell Scientific model CR10 data logger equipped with a multiplexer. The reference temperature $\left(0^{\circ} \mathrm{C}\right)$ is electronically defined by the data logger. The sampling rate used was 2 measurements per second per thermocouple. For temperatures within $0-1000^{\circ} \mathrm{C}$, temperatures are considered correct within 3 to $4^{\circ} \mathrm{C}$ of the measured value. 


\subsection{Experimental procedure}

Pinus pinaster needles were used in all experiments. Special care was taken to guarantee that the fuel bed was as homogenous as possible. In all experiments the fuel load was $500 \mathrm{~g} / \mathrm{m}^{2}$, and the fuel bed's depth was 3 to $4 \mathrm{~cm}$. Fuel load was expressed on a dry basis. Just before the beginning of each experimental run, a sample of the fuel was taken to determine its moisture content. In most experiments the fuel moisture content $(f m c)$ was near 10 to $11 \%$. In some tests, however, $f m c$ was close to $18 \%$.

Line ignition was used. The flame propagated freely along the beginning of the working section. When it entered the $1.70 \mathrm{~m}$ measuring section, usually the flame propagation had already reached steady state conditions. At half of the measuring zone the flame front interacted with the trunk.

During the entire period a video camera recorded the flame progression, and a data logger recorded the thermocouples output.

Two geometric characteristics (flame height and flame angle) of the flame front, as well as its Rate of Spread $(\operatorname{RoS})$, were obtained from the analysis of video images of the propagating flame front [12] using an in-house developed software [13].

Flame angle was defined as the angle between the terrain and the leading surface of the flame (fig. 3). Flame height was defined perpendicularly to the terrain. Only the main body of the flame was considered and the flamelets were disregarded (fig. 3).

Flame height and angle, as well as rate of spread, were obtained in the measuring zone, as mentioned previously. In the near-wake of the trunk (where flames could remain attached to the trunk) only the height of the flame was obtained. There the flame was considered to be attached to the trunk when flames appeared consistently within a user-defined "recirculation zone" (see fig: 4) and its height was a given percentage above the mean flame height elsewhere.

Due to the intrinsic scatter of data in this type of experiments (caused by its turbulent nature and, in particular, by the local heterogeneity of the fuel bed),

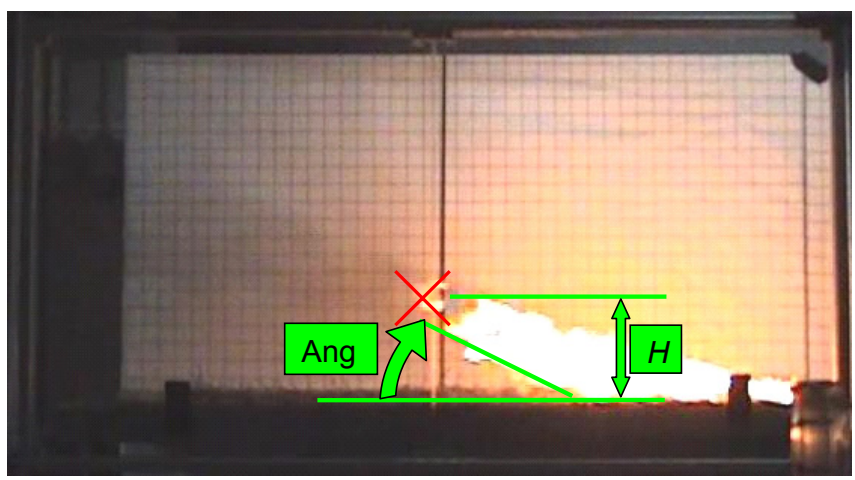

Figure 3: Definition of flame angle and flame height. 


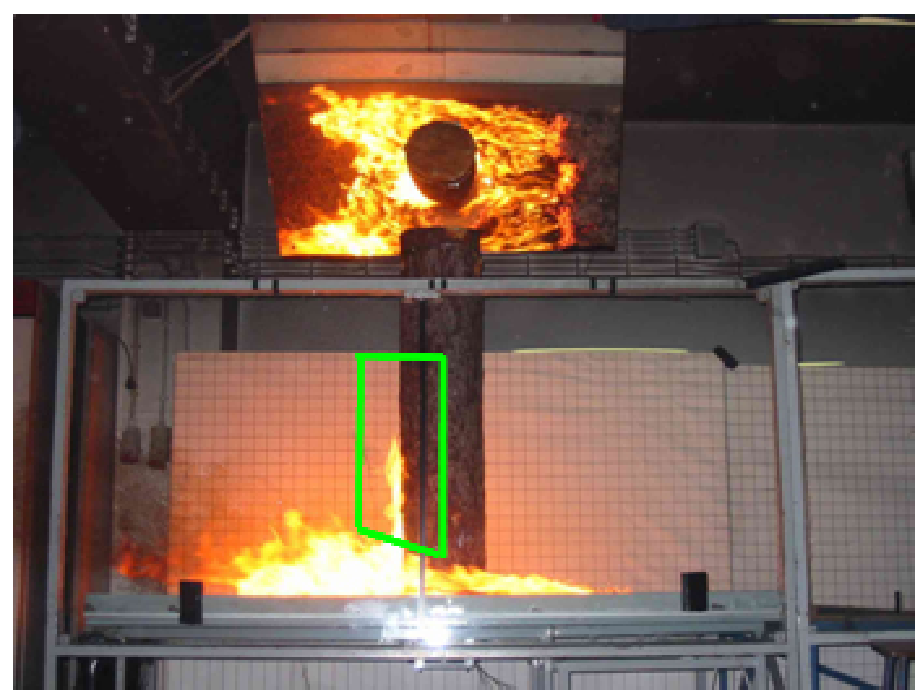

Figure 4: Definition of the zone in the near wake of the trunk where flame could remain attached to the trunk.

every result presented (except for figure 10) is the average of the result of three experimental runs in (assumed) similar conditions.

\section{Results and discussion}

Rate of Spread and geometric characteristics of the flame - flame height and flame angle - were obtained upstream of the trunk, in the zone of the trunk, and downstream of it. The results were compared with results obtained in similar experiments but without the trunk $([12,14])$. Neither $\operatorname{RoS}$ (fig. 5) nor flame height or flame angle (fig. 6) are significantly affected by the presence of the trunk, except in the latter's near-wake. Values of flame height and flame angle were not measured for backing fire propagation because in those conditions it was not possible to clearly and unambiguously distinguish the values for flames inside and outside the trunk's recirculation zone.

Values of $f m c$ for the experiments with wind velocity of 2.0 and $3.0 \mathrm{~m} / \mathrm{s}$ were higher than those for the other runs. This explains why the values in this work are in the lower bracket of those obtained in previous works.

The near-wake of the trunk is a zone where recirculation occurs within a large range of Reynolds numbers [15] (in the experiments with this trunk, the cold flow based $\operatorname{Re}=\frac{U_{\infty} d}{v}$ varied from $7.3 \times 10^{3}$ to $\left.44 \times 10^{3}\right)$. In this region the flame stays attached to the trunk (until the depletion of fuel) and is nearly vertical (see fig. 4 and fig. 7); hence the concept of flame angle is inappropriate. Similarly, in the recirculation zone the concept of $R o S$ does not apply. However, in backing fire propagation when the flame approaches the trunk one part of it enters the 
recirculation zone. That part of the flame is sucked to the trunk and reaches it sooner than the remaining flame that eventually surrounds it. This can be seen in the right chart of figure 5. The velocity of the flame approaching the trunk is about $30 \%$ higher than the $R o S$ for a wind velocity of $-2.0 \mathrm{~m} / \mathrm{s}$, and more that 2.5 times higher for $-3.0 \mathrm{~m} / \mathrm{s}$.
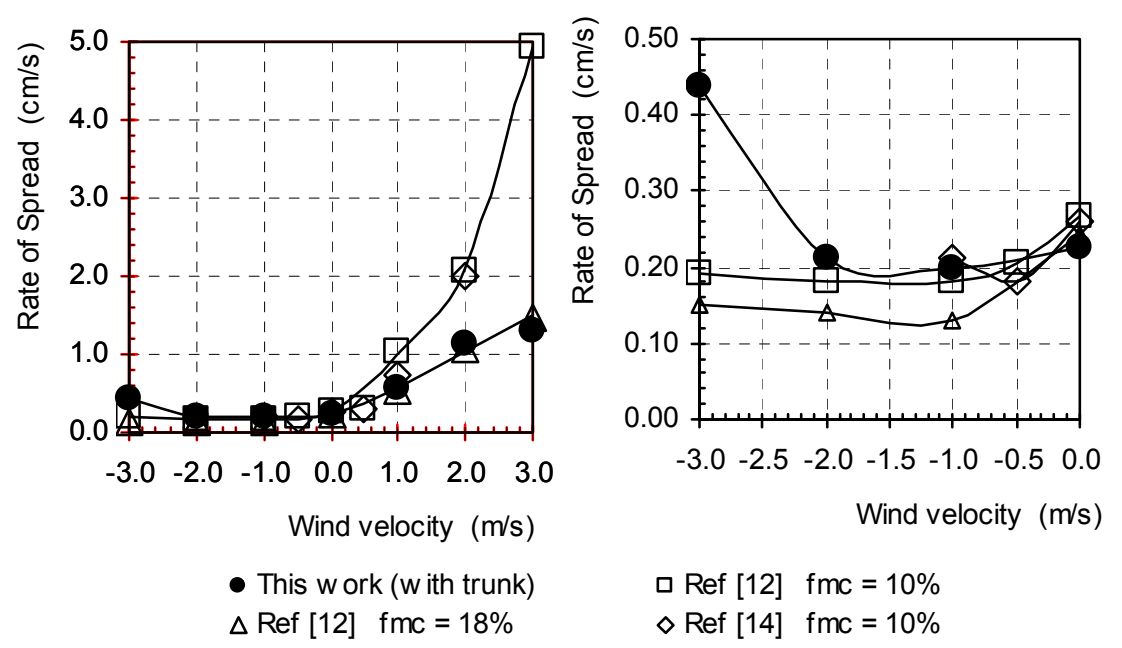

Figure 5: Variation of the rate of spread with wind velocity - for the entire wind velocity range (left) and for the backing fire conditions (right).
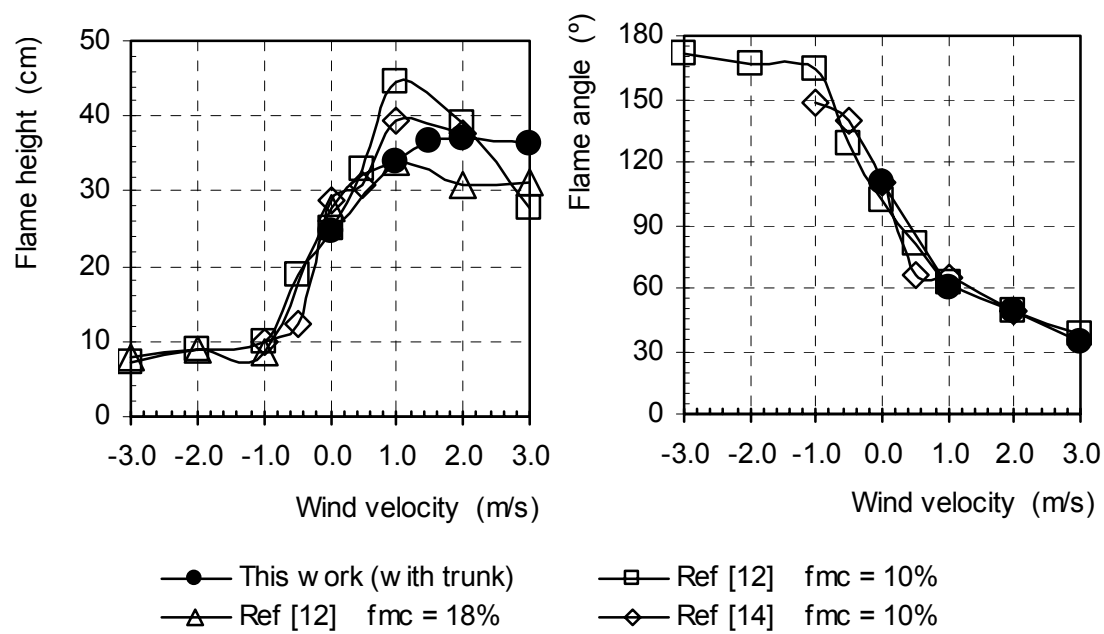

Figure 6: Variation of flame height and flame angle with wind velocity. 


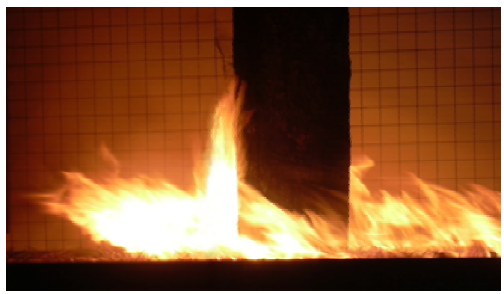

Figure 7: Flame attached to the leeward surface of the trunk in one of the $3.0 \mathrm{~m} / \mathrm{s}$ wind speed tests (flow from the right).
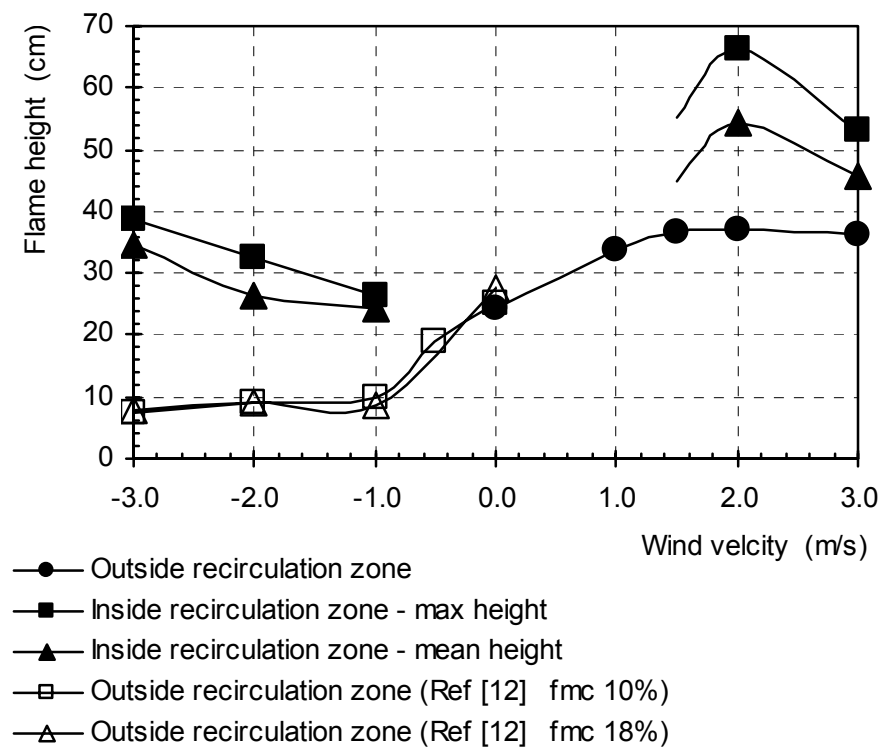

Figure 8: Variation of flame height with wind velocity downstream of the trunk, outside and inside the recirculation zone.

In wind-driven propagation, for wind velocities up to $1.0 \mathrm{~m} / \mathrm{s}$ it was not very easy to identify and to distinguish the flames attached to the leeward side of the trunk from the unaffected flames. Above that wind velocity the flame stays attached to the leeward side of the trunk until the depletion of the fuel. Due to the almost absence of wind velocity in the recirculation zone, the flame is virtually driven by buoyancy effects only. Therefore it is nearly vertical and reaches heights greater than the usual heights reached in regions where buoyancy (vertical) and convection (mainly parallel to the terrain) compete to shape the flame. For backing fire propagation this effect is observed even for low wind speed. Not only the flame is sucked to the trunk (as mentioned), but once attached to the trunk it becomes much taller than the flames outside the recirculation zone. Figure 8 illustrates these points. The black squares show the maximum heights measured in the recirculation zone; the black triangles show 


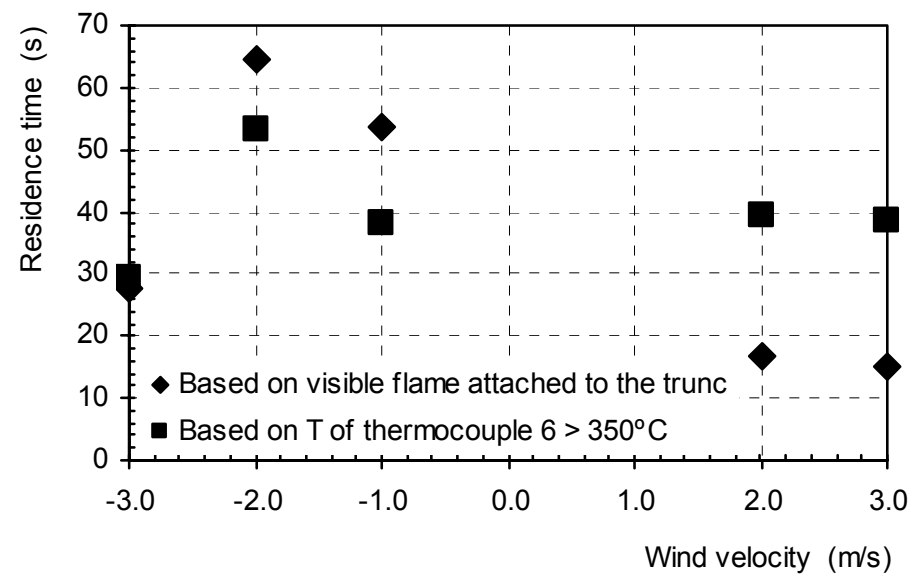

Figure 9: $\quad$ Residence time of flames attached to the leeward side of the trunk (inside the recirculation zone).

the mean value for all the flames whose height is at least $75 \%$ of the height of the tallest flame measured in that particular experimental run.

The residence time $t_{r}$ of the flames attached to the trunk (fig. 9) was obtained from the processed video recordings and also from the temperature profile of thermocouple 6 (located at $100 \mathrm{~mm}$ above the fuel tray, in the leeward side). In this case it was considered that the flame was present during the period in which TC6 $>350^{\circ} \mathrm{C}$. The results are somehow inconclusive. Apparently residence time does not depend on wind velocity (for $U_{\infty}$ up to $3.0 \mathrm{~m} / \mathrm{s}$ ) for wind driven flames. However, for backing fire, residence time seems to increase for wind speed up to $2.0 \mathrm{~m} / \mathrm{s}$ but then decreases. Interestingly, the two defined criteria give results that present the same trends, but different values: $t_{r}$ based on temperature are higher for wind driven flames but lower for backing fire propagation.

Figure 10 shows four of the 33 temperature-time profiles. These profiles help to interpret the mutual influence between surface fire propagation and the trunk. Figure 11 shows the variation with wind velocity of the maximum temperature reached by each thermocouple. Maximum values of $T$ in the windward side of the trunk (T1, T4, T7) are higher for the no-wind situation and decrease with increasing wind speed because the higher the latter, the more the flame is pushed away from the trunk. On the other hand, maximum values of $T$ in the leeward side (T3, T6, T9) are lower for no-wind conditions because increasing wind speed enhances aerodynamic recirculation around the trunk, thus increasing the flames residence time. The thermocouples on the lateral side (T2, T5, T8) show maximum values of $T$ for wind velocity around $1.0 \mathrm{~m} / \mathrm{s}$. For wind velocities $\left|U_{\infty}\right|>1.0 \mathrm{~m} / \mathrm{s}$ the flame is pushed further and further away from the trunk. From 0.0 to $1.0 \mathrm{~m} / \mathrm{s}$ the flame propagation in the windward facing half-trunk side is helped by the wind, hence explaining the maximum at $1.0 \mathrm{~m} / \mathrm{s}$. The thermocouples at the fuel bed level (T1, T2, T3) usually show higher values than 

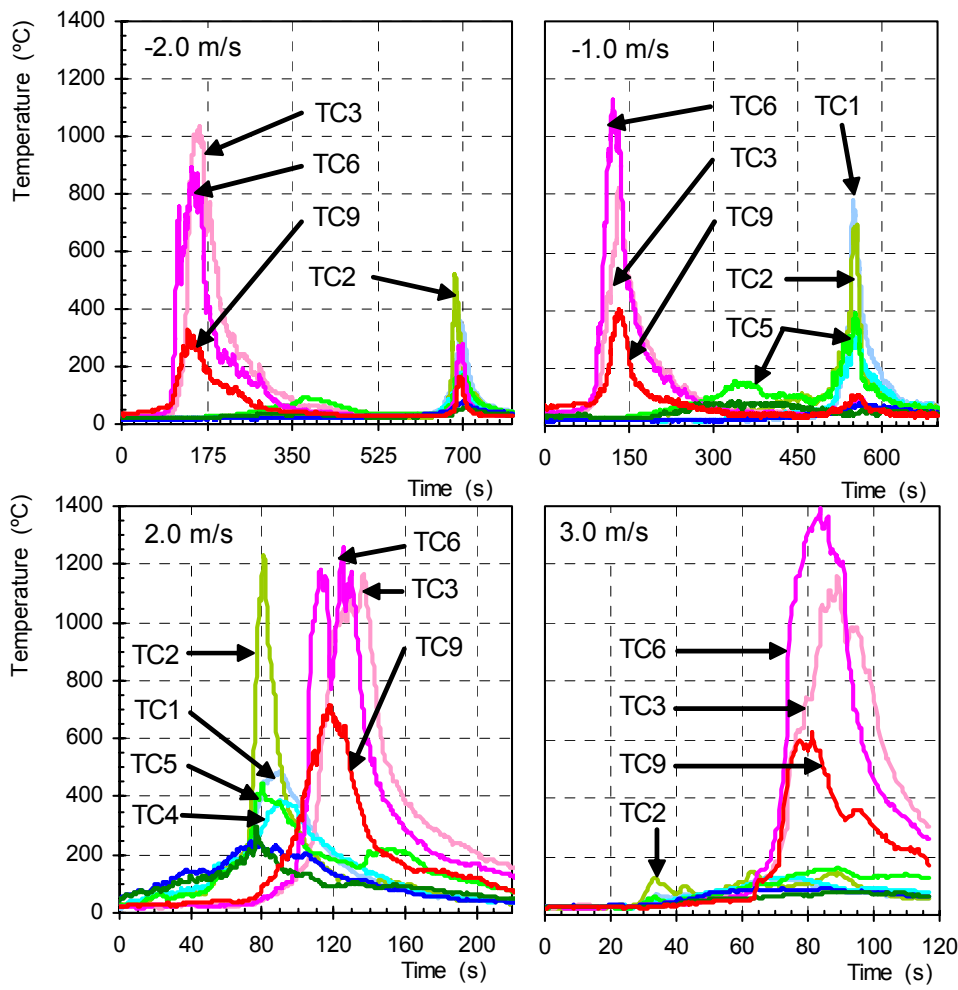

Thermocouple 1

Thermocouple 2

Thermocouple 3

Thermocouple 4

Thermocouple 5

Thermocouple 6

Thermocouple 7

- Thermocouple 8

Thermocouple 9

Figure 10: Temperature-time profiles for four individual experimental runs.

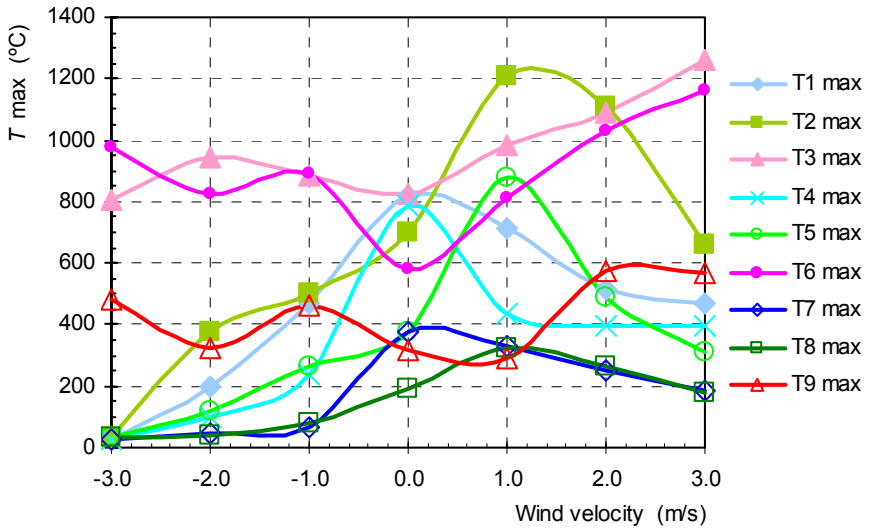

Figure 11: Variation of the maximum temperature in each thermocouple. 


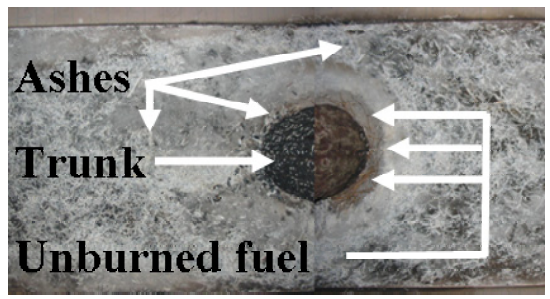

Figure 12: Ashes distribution after burning the fuel bed in one of the $3.0 \mathrm{~m} / \mathrm{s}$ wind velocity experimental runs (flow from the right).

those at $100 \mathrm{~mm}$ (T4, T5, T6). However, in the leeward side (T3 and T6) values are very similar, showing that the attached flame is indeed tall.

Figure 12 shows the ashes distribution on the tray after the $3.0 \mathrm{~m} / \mathrm{s}$ wind velocity experimental run shown in figure 10. It can be seen that there is no combustion on the windward face up to the $90^{\circ}$ (lateral face) of the trunk, which is compatible with the absent peak on the temperature profile of TC1.

\section{Conclusions}

A set of 33 controlled laboratorial experimental runs on the mutual influence between surface fire propagation and a tree trunk has shown that:

- flame propagation is only influenced by the trunk in its near-wake and (for wind speed above, say, $1.0 \mathrm{~m} / \mathrm{s}$ ) in a strip of 2 to $3 \mathrm{~cm}$ (where there is no flame) around the upstream half-side of the trunk;

- wind speed is very low in the recirculation zone. Hence, flames are mainly buoyancy driven, becoming nearly vertical, taller than elsewhere and staying attached to the leeward side of the trunk until depletion of the fuel;

- for backing fire propagation, when the flame approaching the trunk reaches the recirculation zone, it accelerates towards the trunk and remains there until depletion of the fuel;

- the flame may remain attached to the leeward side of the trunk for only a few seconds more than in other parts of the trunk. Overall, it may stay attached for a few dozens of seconds (usually less than a minute). Backing fire situations lead to longer periods. However ...

- ... temperatures reached near the trunk's surface in the recirculation zone may be 300 to $400^{\circ} \mathrm{C}$ higher than elsewhere.

\section{Acknowledgements}

This work was developed under Project no. FP6-018505 (FIRE PARADOX: An Innovative Approach of Integrated Wildland Fire Management Regulating the Wildfire Problem by the Wise Use of Fire: Solving the Fire Paradox). The European Commission financial support is gratefully acknowledged.

Thanks are also due to Ms. Eduarda Freitas for her assistance with the experimental work and valuable discussions, and to the personnel of the SAE/STE workshop at IST. 


\section{References}

[1] Rothermel, R., A mathematical model for predicting fire spread in wildland fuels. Research Paper INT-115, USDA Forest Service, 1972.

[2] Weber, R., Toward a comprehensive wildfire spread model. International Journal of Wildland Fire, 1(4), pp. 245-248, 1991.

[3] Linn, R. \& Harlow, F., Use of transport models for wildfire behaviour simulations. Proc. of the $3^{\text {rd }}$ International Conference on Forest Fire Research, and $14^{\text {th }}$ Conference on Fire and Forest Meteorology, eds. D.X. Viegas, ADAI, University of Coimbra, Portugal, Vol 1, pp. 16-20, 1998.

[4] Larini, M., Giroud, F., Porterie, B. \& Loraud, J., A multiphase formulation for fire propagation in heterogeneous combustible media. International Journal of Heat and Mass Transfer, 41(6-7), pp. 881-897, 1998.

[5] Morandini, F., Santoni, P., Balbi, J., Ventura, J. \& Mendes-Lopes, J., A two-dimensional model of fire spread across a fuel bed including wind combined with slope conditions. International Journal of Wildland Fire, 11(1), pp. 53-63, 2002.

[6] Pastor, E., Zarate, L., Planas, E. \& Arnaldos, J., Mathematical models and calculation systems for the study of wildland fire behaviour. Progress in Energy and Combustion Science, 29(2), pp. 139-153, 2003.

[7] Morvan, D. \& Dupuy, J., Modeling the propagation of a wildfire through a Mediterranean shrub using a multiphase formulation. Combustion and Flame, 138(3), pp. 199-210, 2004.

[8] Dupuy, J. L. \& Morvan, D., Numerical study of a crown fire spreading toward a fuel break using a multiphase physical model. International Journal of Wildland Fire, 14(2), pp. 141-151, 2005

[9] Accary, G., Bessonov, O., Fougère, D., Meradji, S. \& Morvan, D., Optimized Parallel Approach for 3D Modelling of Forest Fire Behaviour. Proc. of the $16^{\text {th }}$ Int. Conf. on Parallel Architectures and Compilation Techniques, pp. 96-102, 2007

[10] The Association for Fire Ecology, www.fireecology.net/pages/13

[11] Ventura, J.M.P., Mendes-Lopes, J.M.C. \& Ripado, L., Interaction between a moving surface fire and a tree trunk. Proc. of the $13^{\text {th }}$ Conf. on Fire and Forest Meteorology, eds. IAWF, Moran, USA, pp. 255-261, 1996

[12] Mendes-Lopes, J.M.C., Ventura, J.M.P. \& Amaral, J.M.P., Flame characteristics, temperature-time curves, and rate of spread in fires propagating in a bed of Pinus pinaster needles. Int. J. Wildland Fire, 12(1), pp. $67-84,2003$

[13] Santos, N.M.G., Fire propagation in forest fuel beds - mutual influence between a surface fire propagation and a pine trunk. MSc Dissertation, IST, Universidade Técnica de Lisboa, Portugal, October 2007 (in Portuguese)

[14] Freitas, M.E.B., Fire propagation in fuel beds of pine needles. MSc Dissertation, IST, Universidade Técnica de Lisboa, Portugal (in preparation)(in Portuguese)

[15] White, F.M., Fluid Mechanics, McGraw-Hill Book Co - Singapure, pp. $388,415,1986$ 